Hal. $300-312$

\title{
PENERAPAN LINEAR PROGRAMMING DALAM PENENTUAN KOMBINASI PRODUK GUNA MEMAKSIMALKAN LABA PADA UD PUTERA SROEDJI JEMBER
}

\author{
Lutfi Hakim \\ Fakultas Ekonomi dan Bisnis Universitas Jember \\ lutfihakim_1505@yahoo.com \\ Hadi Paramu \\ Fakultas Ekonomi dan Bisnis Universitas Jember \\ hadi.feb@unej.ac.id \\ Eka Bambang Gusminto \\ Fakultas Ekonomi dan Bisnis, Universitas Jember \\ ekabagus825@gmail.com
}

\begin{abstract}
The purpose of this study is to analyze the constraints and the optimal product combinations in the production process to obtain maximum profit at UD Putera Sroedji. UD Putera Sroedji is one of the trading companies selling packaged rice that consisted of the $2.5 \mathrm{~kg}, 5 \mathrm{~kg}$, and $25 \mathrm{~kg}$ packaging. In its production process, the company experienced the problem or constraints regarding the less optimal use of resources to reach maximum profit. Linear programming can be used to allocate the limited resources in the production process in order to obtain maximum profit. This research used forecasting and linear programming methods to determine the optimal product combination at UD Putera Sroedji. Results showed that UD Putera Sroedji should produce 200 units of $2.5 \mathrm{~kg}$ packaged rice, 600 units of $5 \mathrm{~kg}$ packaged rice, and 148 units of $25 \mathrm{~kg}$ packaged rice in order to achieve a maximum profit of $\mathrm{Rp} 7,960,977$ per month.
\end{abstract}

Keywords: packaged rice, maximum profit, linear programming, and simplex method.

\begin{abstract}
Abstrak: Tujuan penelitian ini adalah untuk menganalisis kendal-kendala (constraints) dan kombinasi produk yang optimal dalam proses produksi untuk memperoleh laba atau keuntungan maksimal pada UD Putera Sroedji. UD Putera Sroedji merupakan salah satu perusahaan dagang yang bergerak dalam perdagangan beras kemasan, dalam kemasan $2,5 \mathrm{~kg}, 5 \mathrm{~kg}$, dan $25 \mathrm{~kg}$. Dalam proses produksinya, perusahaan menghadapi beberapa masalah atau kendala yang berhubungan dengan penggunaan sumber daya yang belum optimal sehingga laba yang didapatkan belum maksimal. Linear programming dapat digunakan untuk mengalokasikan sumber daya yang terbatas untuk memperoleh laba maksimal. Metode analisis yang digunakan dalam penelitian ini adalah forecasting dan linear programming untuk menentukan kombinasi produk yang optimal. Hasil analisis menunjukkan bahwa UD Putera Sroedji harus memproduksi 200 unit beras kemasan 2,5 kg; 600 unit beras kemasan $5 \mathrm{~kg}$; dan 148 unit beras kemasan $25 \mathrm{~kg}$ untuk mendapatkan laba maksimal sebesar Rp 7.960.977 per bulan.
\end{abstract}

Kata Kunci: beras kemasan, laba maksimal, linear programming, metode simpleks. 


\section{Pendahuluan}

UD Putera Sroedji merupakan salah satu perusahaan yang bergerak dibidang perdagangan beras kemasan yang berada di daerah timur kabupaten Jember. Usaha ini dirintis oleh putra daerah dari Desa Karang Kedawung, Kecamatan Mumbulsari. UD Putera Sroedji menghasilkan produk berupa beras kemasan $2,5 \mathrm{~kg}$, beras kemasan $5 \mathrm{~kg}$ dan beras kemasan $25 \mathrm{~kg}$. Dalam proses produksi, UD Putera Sroedji mengalami beberapa kendala berhubungan dengan sumber daya yang terbatas sehingga keuntungan yang dihasilkan tidak optimal. Manajer pada umumnya memiliki masalah yang berhubungan dengan kapasitas sumber daya ekonomi, yang diantaranya mesin, tenaga kerja, bahan baku, luas gudang, dan lain-lain (Paramu, 2006, dan Aminudin, 2005). Secara umum tujuan perusahaan adalah memaksimalkan keuntungan yang dicapai oleh suatu perusahaan. Salah satu upaya yang dapat dilakukan untuk mengatasi masalah tersebut adalah dengan menggunakan linear programming. Menurut Stapleton, Hanna dan Markusen (2003), linear programming adalah suatu teknik aplikasi matematika dalam menentukan pemecahan masalah yang bertujuan untuk memaksimumkan atau meminimumkan sesuatu yang dibatasi oleh batasan-batasan tertentu.

Beberapa kendala yang dihadapi dalam proses produksi pada UD Putera Sroedji antara lain bahan baku, waktu pengemasan produk, target penjualan masingmasing produk, dan batasan jumlah produksi. Berdasarkan kendala tersebut linear programming merupakan alat yang cocok digunakan pada perusahaan tersebut. Menurut Shintya, Paramu dan Tatok (2017), kendala-kendala yang ada merupakan tujuan atau prioritas yang saling berbenturan.

Berdasarkan uraian yang telah dijelaskan, rumusan masalah yang bisa dikaji adalah bagaimana kombinasi produk dan laba maksimal yang dihasilkan oleh perhitungan menggunakan linear programming pada UD Putera Sroedji dan bagaimana kepekaan solusi optimal yang dihasilkan terhadap perubahan fungsi tujuan dan fungsi kendala. Dengan demikian tujuan penelitian ini adalah mengetahui kombinasi produk dan laba maksimal serta kepekaan solusi optimal terhadap perubahan fungsi tujuan dan fungsi kendala.

\section{Metodologi}

Penelitian ini merupakan penelitian dengan pendekatan eksperimentasi. Pendekatan ini merupakan suatu penelitian yang memanipulasi koefisien suatu variabel. Data yang digunakan dalam penelitian ini adalah data primer dan data 
sekunder. Data primer diperoleh langsung dari pihak-pihak yang berkaitan langsung. Sedangkan data sekunder diperoleh melalui laporan perusahaan, data perusahaan dan data-data yang mendukung penelitian ini. Sumber data diperoleh melalui internal perusahaan untuk mengetahui bahan baku, waktu pengemasan, data penjualan, dan lain-lain.

Metode analisis data yang digunakan dalam penelitian ini adalah linear programming. Langkah-langkah penyelesaian Linear Programming (Agustina, Sriwidadi, dan Teguh, 2013; Heizer, dan Render, 2006) yang dilakukan sebagai berikut :

a. Menentukan variabel keputusan

Merupakan langkah awal dalam Linear programming yaitu menguraikan variabel dalam permasalahan secara detail sehingga didapat variabel keputusan dalam permasalahan Linear programming.

b. Menyusun model matematis Linear Programming yang terdiri dari :

1) Formulasi fungsi tujuan dari permasalahan Linear Programming

$Z_{\max }=\mathrm{C}_{1} \mathrm{X}_{1}+\mathrm{C}_{2} \mathrm{X}_{2}+\mathrm{C}_{3} \mathrm{X}_{3}+\ldots .+\mathrm{C}_{\mathrm{j}} \mathrm{x}_{\mathrm{j}}$

Keterangan :

$Z_{\max }=$ Keuntungan maksimal

$\mathrm{C}_{\mathrm{j}}=$ nilai profit per unit untuk setiap $\mathrm{x}_{\mathrm{j}}$

$\mathrm{x}_{\mathrm{j}}=$ variabel keputusan $\mathrm{ke}-\mathrm{j}$.

$\mathrm{j}=$ banyaknya variabel keputusan mulai dari 1,2,3...j.

2) Formulasi fungsi kendala dari permasalahan Linear Programming

i. $\quad B a h a n$ baku $=a_{11} x_{1}+a_{12} x_{2}+a_{13} x_{3}+\ldots .+a_{j i j} x_{j} \leq b_{1}$

ii. Proses pengemasan produk $=a_{21} x_{1}+a_{22} x_{2}+a_{23} x_{3}+\ldots .+a_{j i} x_{j} \leq b_{2}$

iii. Target penjualan produk $a_{j j} x_{j} \geq b_{3}$

iv. Batasan jumlah produksi $=a_{j i j} \leq b_{4}$

v. Batasan Non-negative :

$\mathrm{X} 1 ; \mathrm{X} 2 ; \mathrm{X} 3 ; \ldots . ; \mathrm{X} \geq 0$

c. Interprestasi Tabel Optimal

1) Solusi Optimal

Solusi Optimal diperoleh dengan mendapatkan nilai variabel keputusan dan nilai fungsi tujuan pada tabel optimal (Aji, Sapta., Kusumaningrum., M, Fifi Herni. 2014). 
2) Informasi tentang Sumber Daya (Resources)

Informasi tentang Sumber Daya (Resources) didasarkan pada nilai slack variable pada tabel optimal. Dalam hal ini, jika slack variable $=0$, artinya penggunaan sumber daya terpakai semua selama proses produksi. Jika slack variables 0 , artinya penggunaan sumber daya selama proses produksi terpakai semua secara keseluruhan. Namun, jika surplus variable $<0$ atau bernilai negatif artinya pada proses produksi mengalami kekurangan sumber daya.

3) Baris Net Profit

Baris net profit di dapat dari nilai shadow price pada tabel optimal. Nilai shadow price mengindikasikan seberapa besar tambahan profit perusahaan yang bisa didapatkan dengan memanfaatkan kapasitas sumber daya yang tersisa.

d. Analisis Sensitivitas

Analisis Sensitivitas merupakan analisis yang dilakukan untuk mengetahui akibat dari perubahan koefisien terhadap kombinasi produk dalam menghasilkan keuntungan. Dimana dalam penelitian ini analisis yang dapat di baca yakni :

1) Perubahan pada koefisien fungsi tujuan dapat dilihat berdasarkan pada nilai lower bound dan upper bound yang ada pada variabel keputusan. Dalam hal ini, perusahaan dapat melakukan perubahaan koefisien fungsi tujuan diatas nilai lower bound dan dibawah upper bound agar solusi optimal tidak terganggu.

2) Perubahan pada Right Hand Side (RHS) didapat dengan melihat nilai lower bound dan upper bound terhadap nilai dari constraints pada tabel optimal. Dengan demikian, perubahan sumber daya yang diperbolehkan oleh perusahaan harus berada pada nilai lower bound dan upper bound agar solusi optimal tetap terjaga.

\section{Hasil dan Pembahasan}

\section{Analisis Data}

Seperti telah dijelaskan pada uraian Bab sebelumnya bahwa penelitian ini menggunakan metode LP (Linear Programming). Tujuan dari penggunaan metode tersebut adalah diharapkan dapat membantu pemilik dalam memproduksi produk yang akan dijual dalam kaitannya dengan kombinasi produk agar mendapatkan laba maksimal. Untuk dapat mengelola data dengan menggunakan LP (Linear Programming) tersebut, maka dilakukan serangkaian penelitian dengan observasi. 
Hasil dari observasi tersebut mendapatkan informasi atau data antara lain data penjualan beras kemasan, tenaga kerja, harga pokok beras dan data laba perusahaan. Dengan data tersebut, maka langkah selanjutnya yang akan dilakukan adalah analisis data. Adapun analisis data yang dilakukan adalah sebagai berikut :

1. Menentukkan Variabel Keputusan

Dalam penelitian ini, dapat diuraikan dari data perusahaan yang ada menjadi tiga variabel keputusan. Hal ini didasarkan pada jenis beras kemasan yang dijual pada UD. Putera Sroedji. Adapun simbol dan definisi variabel keputusan yang digunakan dapat dilihat pada Tabel sebagai berikut :

Tabel 1. Simbol dan Definisi Variabel Keputusan

\begin{tabular}{cc}
\hline Simbol & Definisi \\
\hline$X_{1}$ & Jumlah kuantitas beras kemasan $2,5 \mathrm{Kg}$ \\
$X_{2}$ & Jumlah kuantitas beras kemasan $5 \mathrm{Kg}$ \\
$X_{3}$ & Jumlah kuantitas beras kemasan $25 \mathrm{Kg}$ \\
\hline Sumber: UD Putera Sroedji, 2017
\end{tabular}

2. Formulasi Fungsi Tujuan

Formulasi fungsi tujuan untuk memaksimalkan laba yang diperoleh perusahaan diperoleh dari jumlah nilai laba per unit dikalikan dengan variabel keputusan. Dari perhitungan laba yang dilakukan pada perusahaan maka formulasi fungsi tujuan menjadi:

Maksimumkan: $2.983,33 \mathrm{X}_{1}+5.716,65 \mathrm{X}_{2}+26.583,25 \mathrm{X}_{3}$

3. Formulasi Fungsi Kendala

Fungsi kendala dalam metode Simpleks adalah sebagai berikut:

a. Bahan baku pada UD Putera Sroedji

Bahan baku yang digunakan dalam produksi yang dilakukan oleh UD Putera Sroedji masing memiliki jumlah yang berbeda sesuai yang tertera pada kemasan. UD Putera Sroedji memiliki kuantitas produksi gabah kering sebesar 3 ton/minggu dengan estimasi 2 kali proses penggilingan. Setiap gabah kering yang diproduksi menghasilkan beras dengan persentase sebesar $0.6 \%$ dari jumlah gabah kering. Sehingga diketahui bahwa total produksi gabah sebesar 12 ton/bulan dengan tingkat pengeluaran berupa beras sebanyak 7,2 ton beras.

$$
2,5 X_{1}+5 X_{2}+25 X_{3} \leq 7200
$$


b. Pengemasan produk pada UD Putera Sroedji

Pengemasan produk dilakukan oleh 2 orang karyawan yang dimiliki UD Putera Sroedji. Setiap minggu pengemasan yang dilakukan memiliki jam kerja bersih dipotong jam istirahat sebesar 6 jam untuk hari Jum'at dan 6.65 untuk hari Sabtu. Sehingga dalam seminggu terdapat 12,65 jam kerja masing-masing karyawan, dan dalam sebulan terdapat waktu sebesar 6072 menit untuk pengemasan produk. Dalam pengemasan masing-masing produk memiliki rentan waktu yang berbeda. Untuk beras kemasan $2.5 \mathrm{~kg}, 5 \mathrm{~kg}$ dan $25 \mathrm{~kg}$ membutuhkan waktu sebesar 4 menit, 5 menit dan 8 menit secara berurutan.

Total pengemasan $=(12,65 \times 2) \times 4$ minggu

$$
=40,6 \mathrm{jam} / \mathrm{bulan} \text { atau( } 6.072 \text { menit/bulan) }
$$

$$
4 X_{1}+5 X_{2}+8 X_{3} \leq 6072
$$

C. Target penjualan beras kemasan $2.5 \mathrm{~kg}$

Target penjualan UD Putera Sroedji pada bulan september 2017 sebesar 50 Unit untuk kemasan $2.5 \mathrm{~kg}$. Selain itu, UD Putera Sroedji juga memberlakukan bahwa produksi kemasan $2.5 \mathrm{~kg}$ maksimal hanya 200 unit.

$$
X_{1} \geq 50 ; X_{1} \leq 200
$$

d. Target penjualan beras kemasan $5 \mathrm{~kg}$

Pada bulan september 2017, UD Putera Sroedji memiliki target penjualan sebesar 455 unit kemasan $5 \mathrm{~kg}$. Pembatasan jumlah produksi juga diberlakukan pada produk kemasan $5 \mathrm{~kg}$ yang hanya bisa memproduksi maksimal 600 unit.

$$
X_{2} \geq 455 ; X_{2} \leq 600
$$

e. Target penjualan beras kemasan $25 \mathrm{~kg}$

Kemasan $25 \mathrm{~kg}$ yang dijual oleh UD Putera Sroedji dipatok sebesar 72 unit yang ditargetkan dalam hal penjualan produk.

$$
\mathrm{X}_{3} \geq 72
$$

f. Non-Negativitas

$$
X_{i j} \geq 0
$$

\section{Pembahasan}

a. Solusi Optimal

Solusi optimal merupakan kombinasi produk yang diperoleh berdasarkan hasil perhitungan Linear Programming. Hasil solusi optimal dapat diketahui pada tabel berikut ini. 
Tabel 2. Solusi Optimal Kombinasi Produk

\begin{tabular}{ccc}
\hline Simbol & Definisi & $\begin{array}{c}\text { Kombinasi Produk } \\
\text { Optimal }\end{array}$ \\
\hline$X_{1}$ & Jumlah kuantitas beras kemasan 2,5Kg & 200 unit \\
$X_{2}$ & Jumlah kuantitas beras kemasan $5 \mathrm{Kg}$ & 600 unit \\
$\mathrm{X}_{3}$ & Jumlah kuantitas beras kemasan $25 \mathrm{Kg}$ & 148 unit \\
\hline Sumber: Data diolah, 2017
\end{tabular}

Pada Tabel 2. menunjukkan bahwa UD Putera Sroedji memproduksi produk beras kemasan dengan kombinasi produk yang seharusnya dilakukan, antara lain :

1. Memproduksi produk beras kemasan $2,5 \mathrm{~kg}$ pada bulan September 2017 sebanyak 200 unit.

2. Memproduksi produk beras kemasan $5 \mathrm{~kg}$ pada bulan September 2017 sebanyak 600 unit.

3. Memproduksi produk beras kemasan $25 \mathrm{~kg}$ pada bulan September 2017 sebanyak 148 unit.

Dari ketiga kombinasi produk yang dihasilkan adalah kombinasi produk yang dapat menghasilkan keuntungan maksimal bagi perusahaan sebesar Rp 7.960.977.

b. Nilai Slack atau Surplus Variabel dan Interpretasinya

Nilai slack atau surplus memberikan gambaran tingkat penggunaan sumber/daya yang digunakan dalam proses produksi pada UD Putera Sroedji.

Tabel 3.Slack atau Surplus Variabel

\begin{tabular}{cc}
\hline Constraint & Slack/Surplus Variabel \\
\hline C 1 & 0 \\
C 2 & 1088 \\
C 3 & 150 \\
C 4 & 0 \\
C 5 & 145 \\
C 6 & 0 \\
C 7 & 76 \\
\hline
\end{tabular}

Sumber : Data diolah, 2017

Tabel 3 menunjukkan bahwa nilai slack atau surplus variabel pada masingmasing constraint. $\mathrm{C} 1$ untuk fungsi kendala bahan baku $=0$ menunjukkan bahwa bahan baku telah digunakan semua sesuai porsi masing-masing kemasan tanpa ada kelebihan bahan baku yang menganggur. C2 untuk fungsi kendala penggunaan waktu pengemasan $=1088$ menunjukkan bahwa penggunaan jam tenaga kerja karyawan pada pengemasan masih tersisa 1088 menit yang menganggur. C3 untuk fungsi kendala target penjualan beras kemasan $2,5 \mathrm{~kg}=150$ menunjukkan bahwa produksi kemasan $2,5 \mathrm{~kg}$ telah digunakan semua sesuai target penjualan perusahaan 
dan melakukan produksi tambahan sebanyak 150 unit untuk kemasan $2,5 \mathrm{~kg}$. C4 untuk fungsi kendala batasan jumlah produksi kemasan $2,5 \mathrm{~kg}=0$ berarti bahwa batasan produksi maksimal yang diberlakukan pada perusahaan telah digunakan semua.

C5 untuk fungsi kendala target penjualan beras kemasan $5 \mathrm{~kg}=145$ berarti bahwa produksi kemasan $5 \mathrm{~kg}$ telah digunakan semua sesuai target penjualan perusahaan yang telah ditetapkan dan melakukan tambahan sebanyak 145 unit pada kemasan $5 \mathrm{~kg}$. 66 untuk fungsi kendala batasan jumlah produksi kemasan $5 \mathrm{~kg}=0$ berarti bahwa batasan maksimal produksi kemasan $5 \mathrm{~kg}$ telah digunakan semua. $\mathrm{C} 7$ untuk fungsi kendala target penjualan beras kemasan $25 \mathrm{~kg}=76$ berarti bahwa produksi kemasan $25 \mathrm{~kg}$ telah digunakan semua sesuai target penjualan perusahaan dan melakukan tambahan produksi kemasan $25 \mathrm{~kg}$ sebanyak 76 unit.

c. Shadow Price

Shadow Price/ Opportunity Cost merupakan angka pengganda (multiplieers) yang dapat digunakan oleh perusahaan untuk memanfaatkan kapasitas sumber daya yang tersisa untuk mendapatkan tambahan profit atau keuntungan. Tabel 4 menunjukkan besar perubahan total keuntungan yang terjadi apabila perusahaan melakukan penambahan terhadap jumlah produksi. Fungsi kendala bahan baku (C1) = 1063,33 menunjukkan bahwa besar perubahan keuntungan pada bahan baku sebesar 1063,33. Artinya apabila perusahaan melakukan penambahan bahan baku dapat meningkatkan keuntungan perusahaan sebesar 1063,33.

Tabel 4. Shadow Price/Opportunity Cost

\begin{tabular}{cc}
\hline Constraint & Dual Price \\
\hline C 1 & 1063,33 \\
C 2 & 0 \\
C 3 & 0 \\
C 4 & 325,0051 \\
C 5 & 0 \\
C 6 & 400 \\
C 7 & 0 \\
\hline
\end{tabular}

Sumber : Lampiran 5

C2 untuk fungsi kendala waktu pengemasan $=0$ menunjukkan bahwa setiap penambahan waktu jam tenaga kerja untuk proses pengemasan dapat meningkatkan keuntungan sebesar nol. Artinya penambahan waktu jam tenaga kerja untuk proses pengemasan maka total keuntungan tetap tidak mengalami perubahan. C3 untuk fungsi kendala target penjualan beras kemasan $2,5 \mathrm{~kg}=0$ menunjukkan bahwa 
setiap penambahan 1 unit target penjualan tidak mempengaruhi total keuntungan perusahaan.

C4 untuk fungsi kendala batasan jumlah produksi kemasan $2,5 \mathrm{~kg}=325,0051$ menunjukkan bahwa setiap penambahan 1 unit batasan jumlah produksi kemasan $2,5 \mathrm{~kg}$ maka total keuntungan bertambah 325,0051. C5 untuk fungsi kendala target penjualan beras kemasan $5 \mathrm{~kg}=0$ menunjukkan bahwa setiap penambahan 1 unit target penjualan tidak mempengaruhi total keuntungan perusahaan. C6 untuk fungsi kendala batasan jumlah produksi kemasan $5 \mathrm{~kg}=400$ menunjukkan bahwa setiap penambahan 1 unit batasan jumlah produksi kemasan $5 \mathrm{~kg}$ akan meningkatkan total keuntungan sebesar 400. $\mathrm{C} 7$ untuk fungsi kendala target penjualan beras kemasan $25 \mathrm{~kg}=0$ menunjukkan bahwa setiap penambahan 1 unit target penjualan tidak mempengaruhi total keuntungan perusahaan.

Dengan demikian, dari 7 fungsi kendala yang ada hanya 3 fungsi kendala yaitu fungsi kendala bahan baku, batasan jumlah produksi kemasan 2,5 dan batasab jumlah produksi kemasan $5 \mathrm{~kg}$ yang dapat dijadikan pertimbangan perusahaan dalam pengambilan keputusan. Dalam hal ini, peningkatan atau penambahan sumber daya pada 3 fungsi tersebut akan meningkatkan jumlah keuntungan perusahaan (lbnas, 2014).

d. Analisis Sensitivitas

Analisis sensitivitas dilakukan untuk mengetahui seberapa peka solusi optimal terhadap perubahan pada variabel basis. Hasil pengolahan data menginformasikan batas-batas perubahan koefisien fungsi tujuan dan nilai sisi kanan (RHS) pada masing-masing produk yang tidak mempengaruhi solusi optimal.

1) Rentang Fungsi Tujuan

Hasil analisis rentang koefisien fungsi tujuan menunjukkan batas atas dan batasan bawah perubahan total laba perusahaan yang bisa dilakukan oleh perusahaan dalam melakukan proses produksi.

Tabel 5. Rentang Perubahan Koefisien Fungsi Tujuan

\begin{tabular}{cccc}
\hline Simbol & \multicolumn{3}{c}{ Rentang perubahan koefisien fungsi tujuan } \\
\cline { 2 - 4 } & Koefisien fungsi tujuan & Batas kenaikan & Batas penurunan \\
\hline $\mathrm{X}_{1}$ & $2.983,33$ & Tidak terbatas & $2.658,325$ \\
$\mathrm{X}_{2}$ & $5.716,65$ & Tidak terbatas & $5.316,65$ \\
$\mathrm{X}_{3}$ & $26.583,25$ & $28.583,25$ & 0 \\
\hline
\end{tabular}

Sumber : Data diolah, 2017

Tabel 5 menunjukkan rentang perubahan laba perusahaan yang akan membuat solusi optimal tetap optimal pada masing-masing produk. Produk beras kemasan 2,5 kg memiliki total laba sebesar Rp. 2.983,33 per kemasan. Batas atas dan bawah laba produksi pada produk tersebut adalah masingmasing sebesar tidak terbatas (laba produksi awal + batas kenaikan atau Rp. 
2.983,33 $+\infty$ ) dan sebesar Rp. 325,005 (laba produksi awal - batas penurunan atau Rp. 2.983,33 - Rp 2.658,325). Nilai ini bermakna bahwa laba produksi untuk beras kemasan $2,5 \mathrm{~kg}$ dapat ditingkatkan tidak terbatas dari laba produksi awal dan penurunan laba produksi dapat diturunkan sampai dengan Rp. 325,005 dari laba awal produksi agar hasil optimal tidak terganggu. Dengan demikian, harga terendah beras kemasan yang masih berada pada rentang sebesar Rp 23.674,995. Selama masih diatas Rp 23.674,995 maka perusahaan masih memperoleh keuntungan maksimal dan harga tersebut dapat menjadi dasar pertimbangan keputusan perusahaan agar bisa bersaing dengan harga dipasar.

Total laba produksi pada produk kemasan $5 \mathrm{~kg}$ sebesar Rp 5.716,65. Batas kenaikan dan penurunan laba produksi pada produk tersebut adalah masingmasing sebesar tidak terbatas (laba produksi awal + batas kenaikan atau Rp $5.716,65+\infty$ ) dan sebesar Rp 400 (laba produksi awal - batas penurunan atau Rp 5.716,65 - Rp 5.316,65). Nilai ini bermakna bahwa laba produksi untuk beras kemasan $5 \mathrm{~kg}$ dapat ditingkatkan tidak terbatas dari laba produksi awal dan penurunan laba produksi dapat diturunkan sampai dengan Rp 400 dari laba awal produksi agar hasil optimal tidak terganggu. Dengan demikian, harga terendah yang bisa diterapkan oleh perusahaan sebesar Rp 46.600, harga ini sebagai dasar pengambilan keputusan perusahaan dengan harga pesaing dipasar.

Pada produk kemasan $25 \mathrm{~kg}$ memiliki total laba produksi sebesar Rp $26.583,25$. Pada produk tersebut memiliki batas atas sebesar $\mathrm{Rp} 28.583,25$ per kemasan (laba produksi awal + batas atas atau Rp 26.583,25 + Rp 2.000) dan batas bawah yang bisa dilakukan sebesar Rp 26.583 (laba produksi awal - batas bawah atau Rp 26.583,25 - Rp 0). Nilai tersebut memiliki makna bahwa laba produksi pada produk kemasan $25 \mathrm{~kg}$ dapat ditingkatkan sampai dengan Rp 28.583,25 dari laba produksi awal dan dapat diturunkan sampai Rp 0 dari laba produksi awal agar optimalisasi tidak terganggu. Dengan demikian, harga terendah akan menjadi Rp 203.416,75 per unit pada beras kemasan $25 \mathrm{~kg}$. Harga tersebut sebagai bahan pertimbangan apabila perusahaan ingin melakukan penurunan harga jual agar produk yang dihasilkan bisa bersaing dengan harga yang ditawarkan oleh perusahaan lain. 
2) Rentang Right Hand Side (RHS)

Hasil analisis rentang nilai sisi kanan (RHS) menunjukkan batas atas dan batas bawah jumlah sumber daya produksi yang dapat dilakukan oleh perusahaan sesuai dengan kapasitas sumber daya dan kebutuhan masingmasing produksi.

Tabel 6. Rentang Nilai Sisi Kanan

\begin{tabular}{cccc}
\hline \multirow{2}{*}{ Constraint } & \multicolumn{3}{c}{ Rentang perubahan nilai sisi kanan (RHS) } \\
\cline { 2 - 4 } & Nilai sisi kanan & Batas bawah & Batas atas \\
\hline C 1 & 7.200 & 5.300 & 10.600 \\
C 2 & 6.072 & 4.984 & Tidak terbatas \\
C 3 & 50 & Tidak terbatas & 200 \\
C 4 & 200 & 50 & 540 \\
C 5 & 455 & Tidak terbatas & 600 \\
C 6 & 600 & 455 & 920 \\
C 7 & 72 & Tidak terbatas & 148 \\
\hline
\end{tabular}

Sumber : Data diolah, 2017

Tabel 6 menunjukkan rentang perubahan nilai sisi kanan yang akan membuat solusi optimal tidak terganggu dalam produksi beras kemasan. Kapasitas bahan baku (Constaint 1) sebanyak $7.200 \mathrm{~kg}$ memiliki batas atas dan batas bawah produksi masing-masing sebanyak $10.600 \mathrm{~kg}$ (kapasitas bahan baku awal + batas atas atau $7.200 \mathrm{~kg}+3.400 \mathrm{~kg}$ ) dan $5.300 \mathrm{~kg}$ (kapasitas bahan baku awal - batas bawah atau $7.200 \mathrm{~kg}-1.900 \mathrm{~kg}$ ). Nilai ini menunjukkan bahawa kapasitas bahan baku yang dimiliki perusahaan dapat ditambah sampai $3.400 \mathrm{~kg}$ dari kapasitas bahan baku awal dan dapat diturunkan sampai $1.900 \mathrm{~kg}$ dari kapasitas bahan baku awal agar solusi optimal tetap terjaga (Indrayanti, 2012).

Waktu pengemasan (Constraint 2) yang tersedia pada perusahaan sebanyak 6.072 menit memiliki batas atas dan batas bawah masing-masing tidak terbatas (waktu pengemasan awal + batas atas atau 6.072 menit + tidak terbatas) dan 4.984 menit (waktu pengemasan awal - batas bawah atau 6.072 menit - 1.088 menit). Nilai tersebut menunjukkan bahwa waktu pengemasan pada perusahaan bisa ditambahkan tidak terhingga dari waktu pengemasan awal dan dapat diturunkan sampai 1.088 menit dari waktu pengemasan awal. Constaint 3 menunjukkan target penjualan kemasan 2,5 kg sebanyak 50 unit. Batas atas dan batas bawah pada target penjualan kemasan $2,5 \mathrm{~kg}$ masing-masing sebanyak 200 unit dan tidak terbatas. Nilai tersebut 
menunjukkan bahwa target penjualan bisa diturunkan menjadi 0 unit dan dapat dinaikkan sampai 200 unit dari target penjualan awal.

Batasan produksi yang ditetapkan perusahaan pada produk kemasan $2,5 \mathrm{~kg}$ (Constraint4) sebanyak 200 unit. Batas atas dan batas bawah pada constraint 4 masing-masing adalah 540 unit dan 50 unit. Nilai tersebut menunjukkan bahwa batasan produksi beras kemasan $2,5 \mathrm{~kg}$ dapat diturunkan sampai titik 50 unit dan dapat ditingkatkan mencapai 540 unit.Produk kemasan $5 \mathrm{~kg}$ yang memiliki target penjualan (Constraint 5 ) sebanyak 455 unit. Batas atas pada Constraint 5 adalah 600 unit dan batas bawah adalah tidak terbatas. Artinya, target penjualan produk kemasan $5 \mathrm{~kg}$ dapat dttingkatkan mencapai 600 unit dan dapat diturunkan sampai 0 unittidak terbatas.

Selanjutnya, pada constraint 6 memiliki 600 unit sebagai batasan produksi beras kemasan $5 \mathrm{~kg}$. Pada batasan produksi ini memiliki batas atas dan batas bawah masing-masing adalah 920 unit dan 455 unit. Artinya, perubahan yang diperbolehkan dilakukan perusahaan adalah 455 unit sampai 920 unit agar solusi optimal tetap optimal. Pada Constraint 7 merupakan target penjualan yang ditetapkan pada beras kemasan $25 \mathrm{~kg}$ sebanyak 76 unit. Batas bawah dan batas atas pada constraint 7 masing-masing sebesar 148 unit dan tidak terbatas.

\section{Kesimpulan}

Berdasarkan hasil olah data dapat disimpulkan bahwa Beras kemasan pada UD Putera Sroedji yang memiliki 3 produk antara lain beras kemasan $2,5 \mathrm{~kg}, 5 \mathrm{~kg}$ dan $25 \mathrm{~kg}$ dapat menghasilkan laba maksimal dengan kombinasi produk yaitu beras kemasan 2,5 kg sebanyak 200 unit, beras kemasan $5 \mathrm{~kg}$ sebanyak 600 unit dan beras kemasan $25 \mathrm{~kg}$ sebanyak 148 unit. Dengan kombinasiproduk tersebut maka perusahaan akan memperoleh laba sebesar Rp 7.960.977.

Disisi lain, kombinasi produk hasil analisis menggunakan model linear programming dapat efesien dalam penggunaan sumber daya yang ada dan kebijakan yang akan diterapkan. Sehingga perusahaan memiliki keuntungan yang cukup besar dalam mengoptimalkan operasional perusahaan yang berhubungan dengan kombinasi produk dan perubahan-perubahan terkait laba per produk dan penggunaan sumber daya. 


\section{Saran}

Beberapa saran dapat direkomendasikan pada Pihak UD Putera Sroedji, dimana perusahaan sebaiknya mengimplementasikan keseluruhan dari model linear programming menggunakan metode simpleks dalam pengambilan keputusan terkait kombinasi produk yang akan diproduksi setiap bulannya dalam upaya memaksimalkan laba perusahaan. Sedangkan bagi pihak Peneliti Selanjutnya adalah masih perlu dilakukan penyempurnaan oleh peneliti selanjutnya guna memperoleh hasil yang lebih baik lagi disebabkan keterbatasan penelitian. Oleh karena itu, bagi peneliti selanjutnya diharapkan melakukan analisis lebih dalam dengan cara melakukan penelitian dengan data penjualan per tahun sehingga bisa lebih akurat agar bisa jadi acuann perusahaan.

\section{Daftar Referensi}

Agustina, Erni., Sriwidadi, Teguh. 2013. Analisis Optimalisasi Produksi Dengan Linear Programming Melalui Metode Simpleks. Binus University. Vol. 4 No. 2, November 2013

725-741. http://journal.binus.ac.id/index.php/BBR/article/viewFile/1386/1247. 03 November 2016.

Aji, Sapta., Kusumaningrum., M, Fifi Herni. 2014. Optimisasi Keuntungan Menggunakan Linear Programming di PT Refenery Unit (RU) VI Balongan. Reka Integra. Vol. 01. No. 03, Januari $2014: 232-242$.

Aminudin. 2005. Prinsip-Prinsip Riset Operasi. Jakarta : Erlangga.

Heizer, Jay dan Render, Barry. 2006. Operations Management. Jakarta : Salemba Empat

Ibnas, Risnawati. 2014. Optimalisasi Kasus pemrograman Linear dengan Metode Grafik dan Simleks. MSA. Vol. 2 No. 1, Januari - Juni $2014:$ 1-8.__. 25 Januari 2017.

Indrayanti. 2012. Menentukan Jumlah Produksi Batik Dengan Memaksimalkan Keuntungan Menggunakan Metode Linear Programming Pada Batik Hana. Jurnal IImiah ICTech. Vol.x. No. 1, Januari 2012 : 1-7. http://jurnal.stmikwp.ac.id/files/disk1/1/ictech--indrayanti-18-1-indra.pdf. 25 Januari 2017.

Paramu, Hadi. 2006. Dasar-dasar pemrograman Linear. Jember : Jember University Press.

Shintya Dewi, Aprillia., Paramu, Hadi., Endhiarto, Tatok. 2017. Goal Programming Sebagai Desicion Support System Tingkat Kesehatan Bank PT Bank Bukopin, Tbk. Jurnal Bisnis dan Manajemen Universitas Jember. Volume 11 Nomor 2, Mei 2017 : 209-223.

Stapleton, D.M., Hanna, J. B., \& Markussen, D. (2003). Marketing strategy optimization: Using linearprogramming to establish an optimal marketing mixture. American Business Review. Volume 21 Nomor2 :54-62. 